\title{
English Vocabulary Learning Strategies of Engineering Science Students
}

\section{M.A.S.P. Manchanayaka ${ }^{1}$}

\begin{abstract}
This study investigated the use of vocabulary learning strategies by the students of engineering sciences. It focused on the frequency of use of strategy by them in learning technical terms and investigated the strategies related to success and failure of learning technical terms in the target language, English. In brief, this study enumerated the most frequently used strategies and least frequently used strategies by the participants. A comparison was also made between the highly proficient and less proficient learners in the least and most frequently used vocabulary learning strategies. The results of this study showed that learners prefer to use written repetition, verbal repetition, and bilingual dictionary strategies. A significant use of learning strategies among successful learners was found and the findings showed that proficient l earners used a variety of strategies while less proficient learners used a comparatively smaller number of strategies. Neither the proficient learners nor the low proficient learners are good at employing social strategies to discover the meaning of new technical terms.
\end{abstract}

Keywords: Terms, strategy, cognitive, metacognitive, proficient.

\section{Introduction}

There has been a shift in the field of language learning and teaching with the emphasis being placed on learners and learning rather than on teachers and their

${ }^{1}$ University of Kelaniya, Sri Lanka, susil_manchanayaka@yahoo.com

Date Received: $19^{\text {th }}$ September 2018

Date Accepted: $19^{\text {th }}$ December 2019 
teaching. In parallel to this new shift in interest, how learners process new information and what types of strategies they employ to understand, learn or remember information has been a primary concern of the vocabulary researchers. According to Wedding and Gylys (1983), technical terminology is a specific terminology used to achieve the purpose of communication in the engineering sciences. Technical terminology has two characteristics. First, most technical terms are made of roots and affixes (Yang, 2005). Any single engineering sciences term has at least one root determining its meaning and one or more bound morphemes to change the part of speech or change the meaning of the word. Schmitt (2000) argues that when learners use word parts as an initial wordguessing strategy, they must be careful to check the surrounding linguistic context to see if their guess makes sense or not. Haynes and Baker (1993) also reported that learners sometimes made an incorrect guess about what an unknown word meant in a given text, and then stuck with that erroneous meaning in other contexts even though the surrounding context made clear that it makes no sense. Second, technical terminology is an open set with a number of low-frequency words and newly coined terms.

Since teaching and learning all the words of any language is a hard task, teaching learners vocabulary learning strategies to infer the meaning of unfamiliar terms is more efficient than teaching every vocabulary item they encounter. As Nation (1994) suggested, teaching learners strategies is particularly important when it comes to dealing with low-frequency words. Following Nation, Schmitt (1997) also suggested that high-frequency words should be taught, whereas learning lowfrequency words will still require strategies for inferring their meaning.

\section{Background of language learning strategies}

In most of the studies on language learning strategies, the primary concern has been on "identifying what good language learners report they do to learn a second or foreign language, or, in some cases, are observed doing while learning a second or foreign language." (Rubin and Wenden 1987). The findings of Fan's (2003) study showed that the leaners used the strategies for reviewing and consolidating 
their knowledge of known words and perceived them as useful and that they preferred dictionary strategies. The most proficient learners depended more on sources, guessing and dictionary than the less proficient learners. Regarding the discrepancies between the frequency of use and perceived usefulness in learning $\mathrm{L}_{2}$ vocabulary, the findings revealed the complexity in strategy use.

Schmitt (1997) also reported that the learners used more repetition and dictionary strategies and considered them more useful than other strategies listed in the Vocabulary Learning Strategy Inventory in which 57 strategies have been listed. The strategies of semantic grouping and imagery were less used and regarded as the least useful. There was also some evidence that advanced learners tended to use more complex and meaning-focus strategies than less proficient learners. A number of studies have examined the effectiveness of some specific strategies for learning technical terminology (Fang, 1985; Troutt, 1987; Dunkle, 1983).

Fang and Troutt studied the effectiveness of two strategies, but, two learning strategies alone are not enough for us to see the whole picture of how learners learn technical terms effectively. To gain a general picture of the optimal use of learning strategies for learning technical terms, studies that deal with all the strategies as a group are a supplement to Fang's and Troutt's empirical research.

\section{Language learning strategies: definition}

Many vocabulary research experts defined the term 'language learning strategy'. Wenden and Rubin (1987) define learning strategies as "... any sets of operations, steps, plans or routines used by the learner to facilitate the obtaining, storage, retrieval, and use of information". According to Richards and Platt (1992), learning strategies are "intentional behaviour and thoughts used by learners during learning so as to better help them understand, learn, or remember new information". Faerch et. al. (1983) stress that a learning strategy is "an attempt to develop linguistic and sociolinguistic competence in the target language". According to Stern (1992), "The concept of learning strategy is dependent on the assumption that learners consciously engage in activities to achieve certain goals and learning strategies may be regarded as broadly conceived intentional 
directions and learning techniques". All language learners use language learning strategies either consciously or subconsciously when they process new information and perform tasks in the classroom. Since the classroom is like a problem-solving environment in which language learners are likely to face new input and difficult tasks given by their instructors, learners' attempts to find the easiest way to do what is required, that is, using language learning strategies is an inescapable task.

Could learners use appropriate learning strategies based on the characteristics of technical terms such as guessing from linguistic context and analyzing morphemes when they learn technical terms? Chamot and Kupper (1989) reported that highproficiency language learners know how to use the correct strategies to achieve their goals. Oxford (1985) asserted that successful learners use a range of strategies which are appropriate for their learning tasks. Do high proficiency learners use different strategy patterns from those used by low proficiency learners as found in the studies mentioned above? To have further insight on the use of learning strategies of successful learners, the strategy patterns used by successful and unsuccessful learners may be studied and the attention of the present study was also directed to it.

The purpose of this study was to explore the strategies used by learners to learn technical terms. This study measured the frequency of use of strategy by students of engineering sciences in learning technical terminology and to identify the strategies related to success and failure in learning the terms. In brief, this study attempted to evaluate the most used strategies and the least frequently used strategies by the participants. A comparison was also made between high and low proficient learners. Students of engineering sciences are required to take the course 'Academic English' as a complementary component of the orientation course to begin academic work in English. In order to help teachers to overcome the challenge of teaching technical terms and help engineering sciences students learn technical terms effectively, this study was conducted to explore the strategies used in learning technical terms. 


\section{Methodology}

Some related literature was reviewed and the gap in current knowledge was established. After reviewing the related literature, a questionnaire was developed. This questionnaire was pilot tested for its consistency. After the pilot testing process, the questionnaire was administered to the sample of 100 participants at the University of Moratuwa and they represent middle-income and high-income social strata. However, only 88 questionnaires were used to analyze data as 12 of the administered questionnaires were incomplete. Once the data were collected, they were tabulated and simple statistical analyses were run on the data. The introduction, background to the research problem, review of literature and definition of language learning strategies were written followed by the analysis and interpretation of data. After the analysis and interpretation of data, the discussion and final conclusion was written.

\section{Sample}

Participants in the current study were 88 students of engineering sciences in the first year of their study. They all have done their Advanced Level Examination in the mathematics stream. They specialize in engineering sciences. The sample consisted of male and female participants aged 21-22 years. The participants have passed the English Language as a subject at the Ordinary and General English at the Advanced Level Examination.

\section{Instrumentation}

The instrument used to collect data on strategies is the questionnaire designed by incorporating the Vocabulary Learning Strategy Inventory of Schmitt (1997). The categories of terminology were based on Schmitt's (1997) taxonomy for studying Vocabulary Learning Strategies. In it, social, determination, memory and metacognitive strategies have been listed. The participants were required to answer questions on their strategy use. The questionnaire was made of two 
sections. Part one collected such background information as participants' English proficiency. The second part included 63 items grouped into categories of terminology learning strategies.

\section{Analysis and interpretation of data}

The data were gathered in class by the researcher. A structured questionnaire was used to gather data. Before the questionnaire was administered, a brief explanation of the purpose of the study was provided to the participants. Strategies were categorized according to the VLS Inventory of Schmitt (1997). Each participant's responses were recorded. See the analysis of data and results presented below.

\section{Results}

Most and least used strategies by all participants

\begin{tabular}{|c|c|l|l|c|}
\hline Item & Rank & Category & Strategy & Mean \\
\hline 28 & 1 & Cognitive & Written repetition & 4.22 \\
\hline 29 & 2 & Cognitive & Verbal repetition & 4.01 \\
\hline 07 & 3 & Determination & Bilingual dictionary & 3.79 \\
\hline 21 & 4 & Cognitive & Vocabulary section in textbook & 3.12 \\
\hline 31 & 5 & Cognitive & Take notes in class & 3.01 \\
\hline 4 & 38 & $\begin{array}{l}\text { Social } \\
\text { (consolidating) }\end{array}$ & Ask the teacher for a synonym & 1.49 \\
\hline 34 & 39 & $\begin{array}{l}\text { Cognitive } \\
\text { Put technical terms on physical } \\
\text { objects }\end{array}$ & 1.41 \\
\hline 34 & 41 & $\begin{array}{l}\text { Sognitive } \\
\text { (discovery) }\end{array}$ & $\begin{array}{l}\text { Discover new meaning from group } \\
\text { activity }\end{array}$ & 1.33 \\
\hline 12 & 42 & $\begin{array}{l}\text { Social } \\
\text { (discovery) }\end{array}$ & $\begin{array}{l}\text { Ask the teacher for a new sentence } \\
\text { including the new technical term }\end{array}$ & 1.08 \\
\hline
\end{tabular}

Table 1: 
The table indicates that item 28 (4.21, written repetition) has the highest average frequency, and next is item 29 (4.01, verbal repetition), followed by item 7 (3.79, using a bilingual dictionary), item 21 (3.22, vocabulary section in the textbook). The least preferred strategies are item $12(1.08$, ask the teacher for a new sentence including the new term), and next is item 34 (1.21, listen to tape of word lists), followed by item 8 (1.33, discover new meaning from group activity), item 34 (1.42, label physical objects), item 4 (1.49, ask teacher for synonym of new term). Most and Least Used Strategies by Highly ${ }^{1}$ Proficient Learners

\begin{tabular}{|c|c|c|c|c|}
\hline Item & Rank & Category & Strategy & Mean \\
\hline 21 & 1 & Cognitive & $\begin{array}{l}\text { Use of vocabulary section in the } \\
\text { textbook }\end{array}$ & 4.34 \\
\hline 31 & 2 & Cognitive & Take notes in the classroom & 4.20 \\
\hline 07 & 3 & Determination & Use a bilingual dictionary & 4.30 \\
\hline 29 & 4 & Cognitive & Verbal repetition & 4.10 \\
\hline 28 & 5 & Cognitive & Written repetition & 4.01 \\
\hline 34 & 38 & Cognitive & Label physical objects & 1.30 \\
\hline 38 & 39 & Cognitive & Listen to the tape of the word list & 1.29 \\
\hline 08 & 40 & $\begin{array}{l}\text { Social } \\
\text { (consolidating) }\end{array}$ & $\begin{array}{l}\text { Discover new meaning from group } \\
\text { activity }\end{array}$ & 1.20 \\
\hline 12 & 41 & $\begin{array}{l}\text { Social } \\
\text { (discovery) }\end{array}$ & $\begin{array}{l}\text { Ask the teacher for a sentence with } \\
\text { the word }\end{array}$ & 1.09 \\
\hline 23 & 42 & $\begin{array}{l}\text { Social } \\
\text { (consolidating) }\end{array}$ & Interact with foreigners & 1.09 \\
\hline
\end{tabular}

\section{Table: 2}

The data in table 2 shows that the most preferred strategies for high proficiency learners are item 21 (4.34, vocabulary section in the textbook), item 31 (4.20, take

\footnotetext{
${ }^{1}$ The pre-test administered indicated the level of proficiency the participants had.
} 
notes in class), item 7 (4.30, using a bilingual dictionary), item 29 (4.10, verbal repetition), and item 28 (4.01, written repetition). The least preferred strategies are item 23 (1.09, interact with foreigners), item 12 (1.09, ask the teacher for a sentence including the new term), item 8 (1.20, discover new meaning from a group activity), item 38 (1.29, listen to a tape of word lists), and item 34 (1.30, label physical objects).

Most and Least Used Strategies by Low Proficient Learners

\begin{tabular}{|c|c|l|l|c|}
\hline Item & Rank & \multicolumn{1}{|c|}{ Category } & Strategy & Mean \\
\hline 28 & 1 & Cognitive & Written repetition & 4.7 \\
\hline 29 & 2 & Cognitive & Verbal repetition & 3.65 \\
\hline 16 & 3 & $\begin{array}{l}\text { Social } \\
\text { (consolidating) }\end{array}$ & Ask classmates for meaning & 3.41 \\
\hline 21 & 4 & Determination & Guess from linguistic context & 3.27 \\
\hline 07 & 5 & Determination & Use a bilingual dictionary & 3.27 \\
\hline 34 & 38 & Cognitive & Label physical objects & 1.49 \\
\hline 03 & 39 & Memory & Use the new term in a sentence & 1.49 \\
\hline 38 & 40 & Cognitive & Listen to the tape of word lists & 1.30 \\
\hline 12 & 41 & $\begin{array}{l}\text { Social } \\
\text { (discovery) }\end{array}$ & $\begin{array}{l}\text { Ask the teacher for a sentence } \\
\text { including the word }\end{array}$ & 1.10 \\
\hline 23 & 42 & $\begin{array}{l}\text { Social } \\
\text { (consolidating) }\end{array}$ & Interact with foreigners & 1.07 \\
\hline
\end{tabular}

\section{Table: 3}

The most preferred strategy for low proficiency learners is, as revealed in table 3 , item 28 (4.7, written repetition), item 29 (3.65, verbal repetition), item 16 (3.41, ask classmates for meaning), item 21 (3.41, guess from linguistic context); and item 7 (3.27, use a bilingual dictionary). The least preferred strategies are item 23 (1.07, interact with foreigners), item 12 (1.10, ask the teacher for a sentence including the new term), item 38 (1.30, listen to tape of word lists), item 3 (1.49, use new word in sentences), item 34 (1.49, label physical objects). 


\section{Discussion}

Research into the vocabulary learning strategies revealed a number of positive strategies used by high proficiency learners so that such strategies could also be used by low proficiency learners trying to become successful in language learning. However, there is always the possibility that low proficiency learners can also use the same good learning strategies while becoming unsuccessful owing to other reasons. At this point, it should be emphasized that using the same good language learning strategies does not guarantee that low proficiency learners will also become successful in language learning since other factors may also play a role in successful learning.

The results indicated that there exist major differences in the patterns of learning strategy used by learners of two proficiency levels. High proficiency learners are better at gaining knowledge of a new term. They remember effectively, control, and evaluate their own vocabulary learning strategies better than low proficiency learners do. However, both groups are poor at utilizing social strategies to discover new meanings of the terms they find. Social strategies involve asking for clarification or verification, cooperating with peers, and interacting with native speakers of the target language being learnt.

The lack of use of item 9 (Asking the teacher for a sentence with the word) by the learners has also been influenced by the same factor i.e. educational system and cultural background learners are born into. One study done in China reported that 'Many learners prefer to ask the teacher after the class in order to minimize the loss of face if the question seems unwise' (Scarcella, 1990). In addition, learners do not have enough chances to communicate with native English speakers, so that the item 'interact with foreigners' is relatively unemployed by both proficiency level learners.

Comparing the strategies used by high proficiency learners to those used by low proficiency learners, it was noted that written verbal repetitions were the most and the second most popular strategies among both levels. This finding is in 
accordance with Schmitt's (1997) and Yang's (2005) study which showed that the repetition of a word's written form was used frequently in a Japanese context. This can be attributable to the learning styles encouraged by teachers. Learners are usually required to memorize vocabulary and grammar through repetition. According to Sheridan (1981), the practice of modelling and repetition is usually applied in some classrooms so as to assist learners to develop particular language skills.

None of the textbooks or materials taught to the participants included an audiotape or $\mathrm{CD}$ on which lists of words had been recorded to improve pronunciation and aural understanding of the words. This is why item 34 (listen to the tape of word lists) is one of the least used strategies by participants in the study. This finding is consistent with Yang and Su's study (2003), which presents the view that the main difficulty learners encountered in speaking is their poor pronunciation.

\section{Conclusion}

Language learning strategies, being specific actions, behaviours, tactics or techniques facilitate the learning of the target language. All language learners, it is needless to say, use language-learning strategies. The study indicated that students of engineering sciences, in general, prefer to use written repetition, verbal repetition, and bilingual dictionary strategies. In contrast, asking the teacher for a new sentence including the new term, listening to a tape of word lists, and discovering new meaning from group activity are the strategies least used by the learners. In general, neither low proficient nor high proficient learners use social strategies to learn the meaning of new terms. The study revealed a significant overall use of learning strategies among high proficient learners. Considering Cohen and Aphek (1985), teachers can teach strategies however, they should raise awareness of learners, recognize the most appropriate strategies for every situation and suggest, for example, learners a range of strategies and let learners decide which strategies are good for them. 


\section{References}

Chamot, A. U. \& Kupper, L., 1989. Learning strategies in foreign language instruction. Foreign Language Annals, 22(1), pp. 13-23.

Cohen, A. and Aphek, E., 1985. Retention of second language vocabulary overtime: Investigating the role of mnemonic association. System, 8(1), pp. 221223.

Dunkle, S., 1983. A comparison of medical terminology examination scores of students studying by computer with students studying side by side. ERIC Journal, 25(2), p. 24.

Ellis, R., 1994. The study of second language acquisition. $2^{\text {nd }}$ ed. New York: Oxford University Press.

Faerch, A. and Clause and Kasper, G., 1983. Strategies in interlanguage communication. 3 ed. London: Longman Publishing.

Fan, M. Y., 2003. The frequency of use, perceived usefulness, and actual usefulness of second language vocabulary strategies: A study of Hong Kong learners. The Modern Language Journal, 87(2), pp. 221-226.

Fang, F. S., 1985. The investigation and evaluation of the teaching methods on medical terminology. Taipei: TESOL.

Gylys, B. A. and Wedding, M. E., 1983. Medical terminology. $2^{\text {nd }}$ ed. New York: FA Davies Company.

Haynes, M. and Baker, I., 1993. American and Chinese readers learning from lexical familiarization in English text. In: T. Huckin, M. Haynes \& J. Coady, eds. New Jersey: Albex Publishing Corporation, pp. 130-132.

Nation, P., 1994. The word on words: An interview with Paul Nation. The Language Teacher, 12(6), pp. 5-8.

O'Malley, J. et al., 1985. Learning strategies application with students of English as a second language. TESOL Quarterly, 5(1), pp. 285-287. 
Oxford, R. L., 1985. A new taxonomy for second language learning strategies. $2^{\text {nd }}$ ed. Washington DC: Eric Clearinghouse on Language and Linguistics.

Platt, J. and Richard, J., 1992. Longman Dictionary of Language, Teaching and Applied Linguistics. 5 ed. London: Longman.

Scarcella, R., 1990. Teaching language minority students in the multicultural classroom. 5 ed. New Jersey: Prentice Hall.

Schmitt, N., 1997. Vocabulary learning strategies: Vocabulary, Description, Level and Pedagogy, pp. 201-204. Cambridge University Press.

Schmitt, N., 2000. Vocabulary in language teaching. $2^{\text {nd }}$ ed. Cambridge: Cambridge University Press.

Sheridan, E. M., 1981. Literacy and language reform in the People's Republic of China. Reading Teacher, 20(1), pp. 803-805.

Stern, H. H., 1992. Issues and options in language teaching. $5^{\text {th }}$ ed. Oxford: Oxford University Press.

Troutt, E. D., 1987. Evaluation of keyword mnemonic method for acquisition and retention of medical terminology. Illinois (Carbondale): The University of Southern Illinois.

Wendon, A. and Rubin, J., 1987. Learner strategies in language learning. Language Learning, 21(2), pp. 23-26.

Yang, M. N. and Su, S. M., 2003. A study of Taiwanese nursing students' and inservice nursing professionals' English needs. Journal of Chang Gung Institute of Technology, 2(1), pp. 23-26.

Yang, M. N., 2005. Nursing pre-professionals' medical terminology learning strategies. Taiwan: Asian EFL Journal. 